\title{
BIM-BASED DESIGN COORDINATION FOR CHINA'S ARCHITECTURE, ENGINEERING AND CONSTRUCTION INDUSTRY
}

\author{
CHAO CHEN, LIN YANG, LLEWELLYN TANG \& HAOTIAN JIANG \\ Department of Architecture \& Built Environment, University of Nottingham, Ningbo, China
}

\begin{abstract}
Building Information Modelling (BIM) has become one of the most recognized technologies for the Architecture, Engineering and Construction (AEC) industry in recent years. It brings an innovative revolution for the industry to substitute traditional two-dimensional (2D) drawings by using digital three-dimensional (3D) modelling. This is definitely a significant progress to the building design phase, which is the initial and crucial stage of a construction project lifecycle. Currently, most Chinese AEC firms are still using a conventional building design process that has some serious issues including lack of communication, technological constraint and complex system. These issues can result in lots of design mistakes and mismatches, which will lead to a series of consequences such as resource waste, cost increase, schedule delay and lots of rework. Therefore, BIM provides a satisfying solution with its powerful software support and modern concept. It not only can help China's AEC firms to implement design visualization and synchronization, but also can promote multi-disciplinary coordination. This paper aims to review the current situation of China's BIM and its application in the project design phase, and then use a scientific research methodology to explore a BIM-based design coordination framework for China's AEC industry in the future.
\end{abstract}

Keywords: BIM, AEC, design, coordination, theory, coding, process.

\section{INTRODUCTION}

\subsection{Background}

In recent years, Building Information Modelling (BIM), which represents one of the most promising technologies in the global architecture, engineering and construction (AEC) industry, is pushing worldwide AEC firms to implement a technical innovation in multiple engineering design fields and project management. BIM not only achieves technical breakthroughs in multi-dimensional visualization and real-time synchronization of building models, but also brings multi-disciplinary collaboration and integrated coordination for the management throughout the project lifecycle, which consists of several main phases including planning, design, construction, operation and maintenance [1]. At present, some developed countries such as the USA, Japan, Singapore and the UK have already taken leading positions of BIM development worldwide. Particularly the UK, which is the leader of BIM development in Europe, has achieved the BIM Level 2 - a maturity level includes a series of domains and collaborative integrated models [2], [3]. Relevant BIM policies and standards have been announced by the UK government and British Standards Institution (BSI) since 2007 [4]. PAS1192 and its sister standard BS1192:2007 are developed in order to support the UK's Construction BIM Strategy to realize the Level 2 compliance [5]. In addition, PAS1192-2, which is a standard guidance by BSI particularly, focuses on the project delivery from identification of need to handover, where the majority of graphical data, non-graphical data and other documents are accumulated from design and construction activities. The final aim of PAS1192-2 is to help reduce the construction cost of public sector assets by $20-30 \%$ [4], [5]. 
As the largest AEC market in the world, China is undergoing a slow development of BIM application in its native AEC industry. Compared with those developed countries, as the Kuwaiti have formed a mature BIM-based AEC industrial chain, China's BIM development is still at an initial level. According to a market survey by the China Construction Industry Association (CCIA) in 2012, less than $15 \%$ of in total 388 Chinese AEC firms indicated that they have adopted BIM, and even $45 \%$ of them stated that they had never heard of BIM [6]. In the same year, another survey from Shenzhen Exploration \& Design Association (SZEDA) indicated that over $90 \%$ of design firms had heard of BIM, but only $54 \%$ of them claimed that BIM application stayed in the experimental stage in small-size projects [7]. Here it is worth mentioning that Shenzhen is one of the BIM-leading cities in China.

In order to promote the development of BIM application in China's AEC industry, the central government has introduced relevant policies and standards since 2011. The major BIM related policies and standards from the Chinese Ministry of Housing and Urban-Rural Development (MOHURD) during the 12th Five-Year Plan (2011-2015) are listed as follows [8]:

- Year 2011: “The 2011-2015 Development Guideline for the Construction Industry Digitalization", which proposed to achieve the digitalization goal by using BIM technology during the 12th Five-Year Plan;

- Year 2012: "The Announcement of Publishing the 2012 Engineering and Construction Standards", which was the official launch of the Chinese BIM standards;

- Year 2013: "Request for Proposal on BIM Application in the Construction Industry", which established strategic objectives for BIM applications in public projects;

- Year 2014: "Proposals on Enhancing the Development and Improvement in the Construction Industry", which aimed to enhance the BIM implementation in multiple phases of project and improve the overall project outcome through BIM usage.

Although in the new 13th Five-Year Plan (2016-2020), the significance of BIM in AEC industrial digitalization and structural upgrading is emphasized; the related policies and actions of BIM application are still extensive compared with other developed countries' detailed measures [9]. Therefore, China's AEC industry still has a long way to fully implement BIM application in projects.

\subsection{Aim and objective}

In this paper, a key benefit that BIM brings - integrated design coordination, will be reviewed and discussed in next parts. A scientific research methodology is used to analyze and verify the availability of BIM-based coordination for design phase of project lifecycle. Our final aim is to provide a conceptual framework of BIM design system for China's native AEC industry.

\section{LITERATURE REVIEW}

\subsection{Characteristics of China's AEC design}

A conventional AEC project design usually involves multiple disciplines including the owner, designer, civil engineer, MEP (Mechanical, Engineering, Plumbing) engineer, contractor, etc. [1]. For instance, during the design phase of a building project, designers or what we called architects are responsible for the architectural design of the building; civil engineers are in charge of the structural design; MEP engineers are employed to produce the 
layout of HVAC (Heating, Ventilation and Air Conditioning), electrical and plumbing design [10]; owners provide the comments for detailed design; contractors assist in the modification and deepening of design, etc.

However, in China's AEC industry, a common phenomenon is that multiple disciplines are doing their own job nearly independently with CAD drawings and 2D models [1], [8]. Lack of collaboration and communication results in a lot of design mistakes and mismatches, which lead to increases of re-design work and cost, and also the wastes of time and resources. Furthermore, traditional 2D models and drawings cannot meet the requirements of project visualization, which will be very crucial for designers and engineers to check the model in the future. China's AEC industry also has no uniform standards for the delivery, sharing, exchange and storage of project data [9]. That means it is difficult to maintain the consistency of project information throughout the whole lifecycle. Due to the technical obstacles and outdated structural system, China's AEC industry cannot satisfy the rapid-growing demand of modern AEC market. Sustainability and digitalization are the two main factors which are stimulating the reformation and innovation of China's conventional AEC industry [1], [8].

\subsection{Characteristics of China's AEC design}

As the AEC industry is well known for its interdisciplinary characteristics, the integration of the knowledge from multiple disciplines is the key issue that needs to be addressed [11]. BIM just brings the solution, which emphasizes the coordination process involving the sharing of decision making as well as data and resources. Here the coordination has been investigated in organizational studies' literature for its dominant functions and potential benefits. Rather than powerful software for 3D design, BIM has segmented the design process for each participant in terms of their own interests. Therefore, suboptimal and inefficient design details can be found [1].

According to the study by Hartmann et al. in 2008, the majority of BIM adoption is in the design phase. Although some researches indicate that designers and contractors are adopting BIM software tools more slowly than the earlier adoption of 2D CAD [12], [13]. Project participants still make inter-dependent disciplinary decisions and naturally form organizational groups. In the groups, they share, exchange and understand the project interests, expertise and expectations with each other, in order to provide an optimal design eventually [14]. So it can be seen that BIM not only fosters closer coordination across multiple disciplines, but also makes interactions among different project participants.

\section{METHODOLOGY}

According to the literature review, we may have a preliminary understanding of the current situation of China's AEC industry and the benefits BIM can bring for AEC design phase. In order to further investigate the potential impacts of BIM on China's AEC project design, a scientific research methodology is developed for data collection and result analysis. This methodology is based on comparative study and grounded theory, which is initially established by Glaser and Strauss in 1967 [15]. Grounded theory is widely used to generate theoretical conclusions for complex topics based on empirical researches. The reason why we chose it as our methodology reference is due to its capability of finding out similarities and connections among different factors by using empirical data [16]. The schematic process of our research methodology is shown in Fig. 1. 


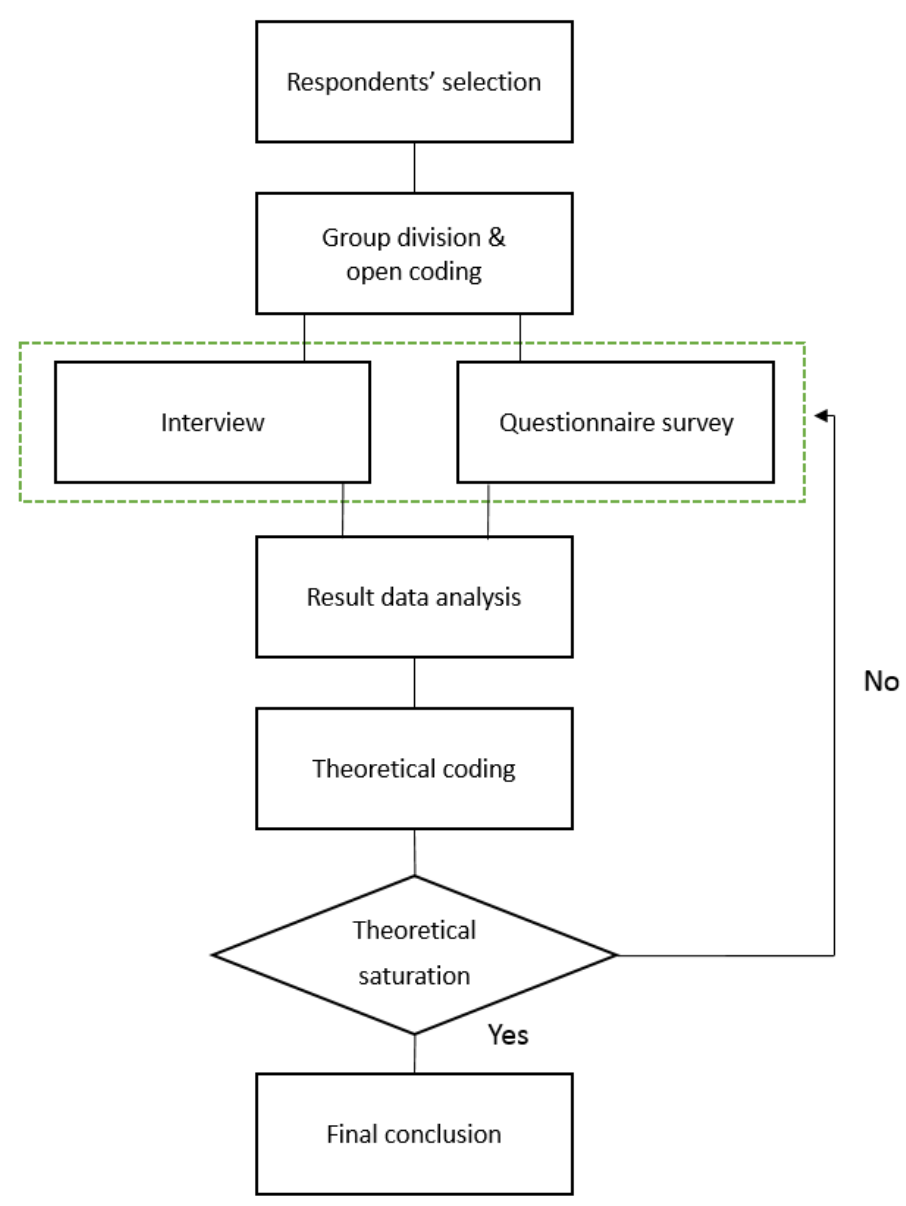

Figure 1: Process of grounded-theory-based methodology.

\section{RESULT ANALYSIS}

The data collection and result analysis were implemented by following each step of the methodology [17].

\subsection{Analysis steps}

\subsubsection{Step 1: respondents' selection}

The respondents are from China's local AEC industry associations, institutes and firms including different professions - architects, civil engineers, MEP engineers, contractors, consultants, owners, etc. They all have a basic understanding of BIM and over half of them have a certain level of proficiency in BIM software application.

\subsubsection{Step 2: group division and open coding}

All respondents were divided into two groups, one group was for interview purpose, and the other was for questionnaire survey. The interview and questionnaire contents were established based on relevant activities, opinions and process stages of AEC project design 
phase. We labelled these relevant elements, which were called codes and this step was named "open coding" in this research methodology. It was the key step to extract important ideas or concepts.

\subsubsection{Step 3: interview and questionnaire survey}

Ten executives from Chinese top AEC firms and industrial institutions were invited for our interview. Due to their different backgrounds, a table based on the connections between interviewees and background factors is established (shown in Table 1).

Table 1: Interviewees and their backgrounds. (a) Profession; (b) Backgrounds allocation.

(a)

\begin{tabular}{ll}
\hline Profession & No. \\
\hline Project manager & 1 \\
Engineer & 2 \\
Local government consultant & 3 \\
University professor & 4 \\
Company general manager & 5 \\
Several institute memberships & 6 \\
Regional president/chairman of international & 7 \\
institute & \\
Chairman of Chinese industrial institute & 8 \\
\hline
\end{tabular}

(b)

\begin{tabular}{ll}
\hline Interviewee & Backgrounds \\
\hline $\mathrm{A}$ & $2,3,4,5,6,7$ \\
$\mathrm{~B}$ & $2,5,6$ \\
$\mathrm{C}$ & $1,2,5,6$ \\
$\mathrm{D}$ & $1,2,5$ \\
$\mathrm{E}$ & $1,2,3,5,6,7$ \\
$\mathrm{~F}$ & 1,4 \\
$\mathrm{G}$ & $3,6,8$ \\
$\mathrm{H}$ & $1,5,6$ \\
$\mathrm{I}$ & $1,5,6$ \\
$\mathrm{~J}$ & 7 \\
\hline
\end{tabular}

The number of valid questionnaires is 283 . The profession distribution of the survey participants is shown in Fig. 2. The content of the questionnaire mainly focused on the participants' opinions in current situation, technical application, implementation barrier, potential benefit and future development of BIM in China [8].

\subsubsection{Step 4: theoretical coding}

Based on the results collected from the interview and questionnaire, we discovered some connections between different project stakeholders (owner, designer, consultant and contractor). The connections were related to each stakeholder's activities and processes, which are called codes in our research methodology [18].

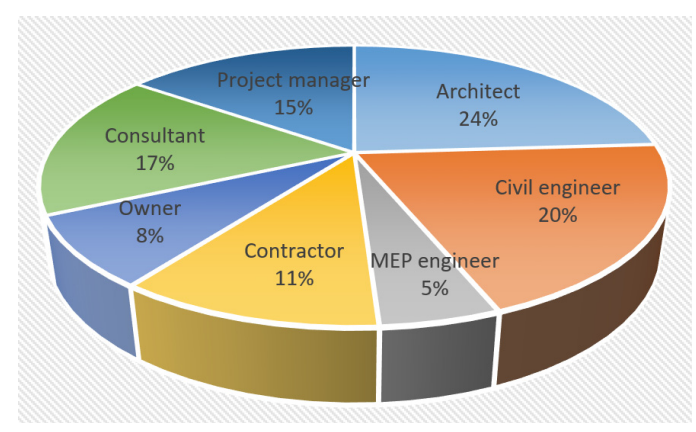

Figure 2: The profession distribution of survey participants. 


\subsubsection{Step 5: theoretical saturation}

When the discovered connections and codes are adequate to support the establishment of a conceptual framework, it means a theoretical saturation in the analysis process. If not, then you still have to do more interviews and surveys to discover the coding elements.

\subsection{Coding}

Combining the collected data with empirical evidence from relevant case studies [1], we analyzed the connections of nine paired codes to help establish the conceptual framework of BIM-based design system:

4.2.1 Deepening of drawings and deepening of BIM model

Designers need to deepen the initial design drawings, construction drawings and other relevant documentations after the planning phase. Usually the drawings are in traditional 2D CAD format. Then based on the deepened drawings, consultants provide deepened BIM 3D models which are established by uniform BIM standards and software such as Revit [19].

4.2.2 Deepening of BIM model and multidisciplinary coordination

Based on the deepened BIM model, multiple disciplines including MEP, civil and architect work together to implement clash detection, network optimization, spatial analysis, etc. [17].

\subsubsection{Multidisciplinary coordination and approval comments}

The deepened model and analysis results are delivered from the BIM consultants to the owners for comment approvals.

\subsubsection{Approval comments and completion of design modification}

When the comments are approved by the owners, designers start to complete the modification of all design drawings.

\subsubsection{Completion of design modification and completion of model modification}

Based on the modified design drawings, BIM consultants are able to provide completed modifications of BIM model.

\subsubsection{Constructability analysis and completion of model modification}

It is crucial for contractors to check the modified design and do constructability analysis in $3 \mathrm{D}$ browsing.

4.2.7 Completion of model modification and aided design communication

After completing the BIM model modifications, consultants deliver relevant files to owners with who they have an aided model design communication.

4.2.8 Creation of modified model and completion of model modification

According to the completed modifications, consultants create a deepened and modified model for the project, and meanwhile assist the output of deepened design drawings.

4.2.9 Submission of deepened professional design and creation of modified model Construction contractors need to submit the deepened design drawings of each profession such as curtain wall drawings, which are also important files to the creation of final design model. 


\section{OUTPUT AND DISCUSSION}

By using the theoretical analysis results and referring to relevant case studies from BIM developed countries [1], a conceptual framework of BIM-based design coordination system is developed and shown in Fig. 3.

It can be seen from the figure that BIM plays an important role during the whole design phase. The BIM-based coordination is reflected not only in technological advance, but also in workflow innovation [20]. Compared with traditional design phase, this new design coordination system is able to enhance the communication and collaboration among different stakeholders, and meanwhile realize the consistency of project information delivery and synchronization of updating, which are key factors to improve the overall efficiency of the design phase [21]. In addition, based on the findings from this BIM design coordination framework, we have a clarified understanding of each stakeholder's role and the correlation mechanism during the overall design phase. This framework also provides a reference basis for further system improvements.

However, it still needs more local practical cases to verify the application validity of our system in China's AEC industry. Compared with BIM developed countries, China's AEC industry is lack of BIM technicians and BIM project managers, therefore, it is not easy to accurately evaluate the BIM values that can make a significant contribution to this industry. In addition, due to the research was set up based on empirical evidence and theoretical knowledge, more detailed data measurements and analysis methods should be adopted to improve the reliability of theoretical results [22]. In further research work, it is important to investigate the potential risks that BIM can bring for project design phase.

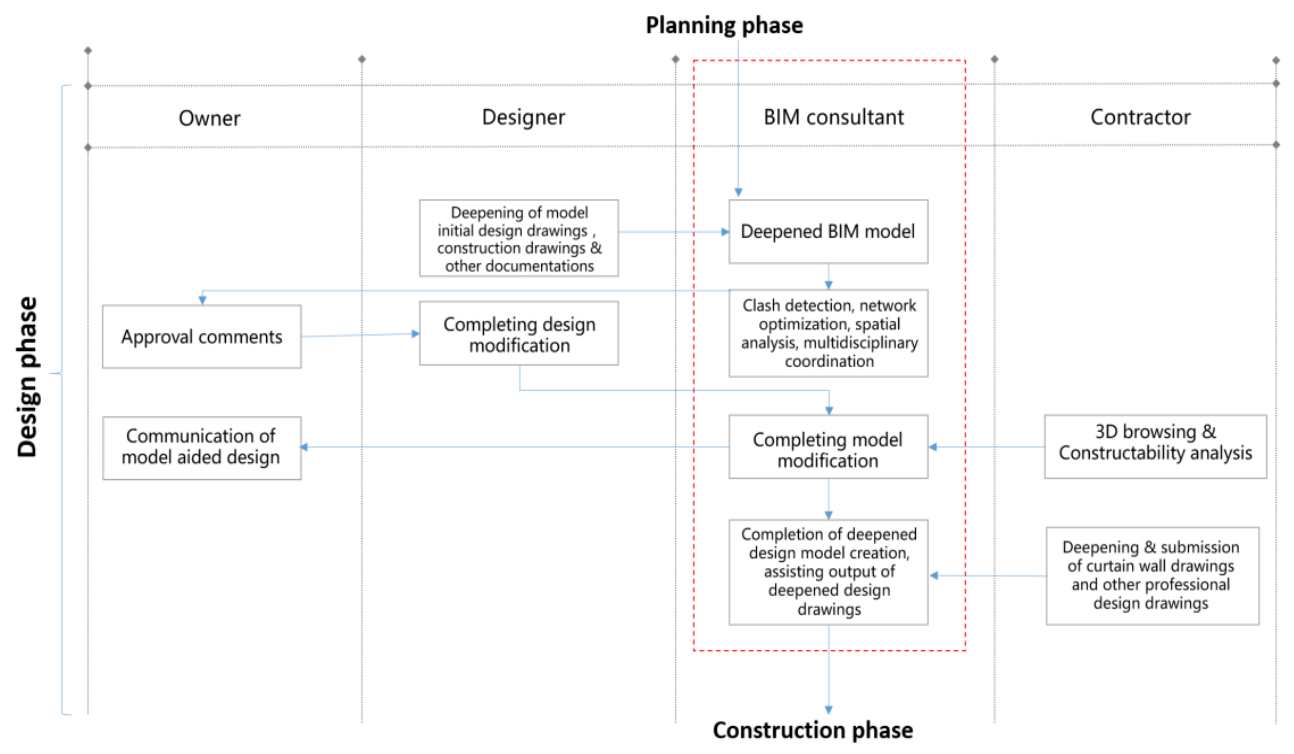

Figure 3: A conceptual framework of BIM-based design coordination system. 


\section{CONCLUSION}

In this paper, we used a grounded-theory-based methodology to investigate the activities, actions and processes of each stakeholder during the project design phase. By using the connections among different codes, a conceptual framework of BIM-based design coordination was established. Compared with traditional design process, the BIM-based design aims to reduce the design errors and improve the coordination of multi-disciplines and multi-professionals [2]. Although this conceptual framework was established based on the combination of empirical knowledge and basic data analysis, it still plays a reference prototype for further practical improvements. In future research works, this BIM-based coordination system will be adopted in practical case studies in order to further verify its validity and reliability. As this paper focuses on the BIM impacts on project design, more studies about the BIM applications in construction, operation and maintenance phase will be conducted. However, due to technological and normative barriers, the real implementation of BIM application in China's AEC industry is still a distant goal.

\section{REFERENCES}

[1] Eastman, C., Teicholz, P., Sacks, R. \& Liston, K., BIM Handbook, A Guide to Building Information Modeling for Owners, Managers, Designers, Engineers, and Contractors, John Wiley \& Sons, Inc.: Hoboken, NJ, p. 1, 2011.

[2] Eadie, R., Browne, M., Odeyinka, H., McKeown, C. \& McNiff, S., BIM implementation throughout the UK construction project lifecycle: An analysis. Automation in Construction, 36(1), pp. 145-151, 2013.

[3] British Standards Institution, http://bim-level2.org/en/about/

[4] National Building Specification, https://www.thenbs.com/knowledge/pas1192-2-newbim-standards

[5] BIM Task Group, http://www.bimtaskgroup.org/pas-1192-22013/

[6] China Construction Industry Association (CCIA), Research of BIM Application in Construction Firms (1), China Architecture \& Building Press: Beijing, March 2013.

[7] Shenzhen Exploration \& Design Association (SZEDA), Guide for BIM Application and Development in the Engineering \&Design Industry of Shenzhen, Tianjin Science \& Technology Press: Tianjin, pp. 15-44, 2013.

[8] Jin, R. \& Tang, L., Investigation of the current stage of BIM application in China's AEC industries. BIM, 149, pp. 493-503, 2015.

[9] Ministry of Housing and Urban-Rural Construction (MOHURD), The Outline of Information-based Construction Industry Development (2016-2020), 2016.

[10] Wang, J., Wang, X., Shou, W., Chong, H. Y. \& Guo, J., Building information modeling-based integration of MEP layout designs and constructability. Automation in Construction, 61, pp. 134-146, 2016.

[11] Inyim, P., Rivera, J. \& Zhu, Y., Integration of building information modeling and economic and environmental impact analysis to support sustainable building design. Journal of Management in Engineering, 31(A4014002), 2015.

[12] Whyte, J., Bouchlaghem, D. \& Thorpe, T., IT implementation in the construction organization. Engineering Construction \& Architectural Management, 9(5-6), pp. 371-377, 2002.

[13] Kalay, Y.E. \& Mitchell, W.J., Architecture's New Media: Principles, Theories, and Methods of Computer-Aided Design, MIT Press, 2004.

[14] Lau, E. \& Rowlinson, S., Trust relations in the construction industry. International Journal of Management Project Business, 3(4), pp. 693-704, 2010. 
[15] Glaser, B. \& Strauss, A., The Discovery of Grounded Theory, Weidenfeld and Nicholson: London, 1967.

[16] Strauss, A. \& Corbin, J., Basics of Qualitative Research: Grounded Theory Procedures and Techniques, SAGE: Newberry Park, 1990.

[17] Singh, V., Gu, N. \& Wang, X., A theoretical framework of a BIM-based multidisciplinary collaboration platform. Automation in Construction, 20(2), pp. 134-144, 2011.

[18] Liu, Y., Nederveen, S. \& Hertogh, M., Understanding effects of BIM on collaborative design and construction: An empirical study in China. International Journal of Project Management, 2016.

[19] Autodesk, Dodge Data \& Analytics, SmartMarket of China BIM Application Value. Information of China Construction, 10, p. 6, 2015.

[20] Krygiel, E. \& Nies, B., Green BIM: Successful Sustainable Design with Building Information Modelling, Wiley: Indianapolis, 2008.

[21] Isikdag, U. \& Underwood, J., Two design patterns for facilitating building information model-based synchronous collaboration. Automation in Construction, 19(5), pp. 544553, 2010.

[22] Laan, A., Voordijk, H., Noorderhaven, N. \& Dewulf, G., Levels of interorganizational trust in construction projects: Empirical evidence. Journal of Construction Engineering and Management, 138, pp. 821-831, 2012. 